\title{
A Descriptive Study to Assess the Prevalence of Alcoholism and Relapse Precipitants among Alcoholic Persons in Selected Community, Jalandhar, Punjab.
}

\author{
Baljinder kaur ${ }^{1}$, Jaspreet kaur Sodhi ${ }^{2}$ \\ ${ }^{l}$ Associate professor, MHRDAV, Jalandhar. ${ }^{2}$ Associate Professor I.N.E, G.T.B.S $\odot$ H, Ludhiana.
}

\begin{abstract}
A descriptive study to assess the prevalence of alcoholism and relapse precipitants was conducted on total sample of 1262, out of which 1162 were males of age group of 20 -50 years and above and 100 sample of alcoholic with alcoholic relapse at Sarai Khass, near CHC Kartarpur, Jalandhar, Punjab. Information was collected with the help of self structured checklist. The tool for data collection included socio-demographic variables and checklist consisting of items related to measure the relapse precipitants among males. Structured Check list used to collect data contain 6 items regarding assessment of relapse precipitants among males. Data were coded, validated and analyzed using descriptive statistics. Based on major findings it can be concluded that $51.11 \%$ persons were alcoholics and $18.82 \%$ were relapse cases.
\end{abstract}

\section{Introduction:}

Alcohol is used as social lubricant and relaxation facilitator, which provides pharmacological pleasure but when the same alcohol is misused, it turns into an evil, which is sufficiently inflammable to burn the families, society and country. (Utalbasha. N. Dhandargi, 2007). ${ }^{1}$

Alcoholism is one of the major health and social problem seen all over the world. Globally there are 140 million alcohol dependents and $78 \%$ of them are not treated. The second National Family Health Survey (NFHS - II) conducted in years 1998 and 1999 indicate that among the Indian population 17\% of men and 2\% of women aged 15 and above are consuming alcohol (Sai Baba, 2001). Alcohol use has been identified as one of the global risk factor accounting for $1.5 \%$ of all deaths in the world and $3.5 \%$ of disability adjusted life years and $4.0 \%$ of all global burden of disease (Rehm, 2004) ${ }^{2}$

In India it has been estimated that $40-50 \%$ of all males drink alcohol as compared to less than $1 \%$ of female adults. So alcoholism appears to be predominately a male disorder especially in India. In any individual case, behavioural factors may be more important than others. A childhood history of attention deficit / hyperactive disorder or conduct disorder or both increases a child's risk for an adult. Personality disorder especially antisocial personality also causes alcoholism in a person. According to psychoanalytical theory, fixation at oral stage causes alcoholism. Some social settings commonly lead to excessive drinking, college dormitories and military are two examples of settings where excessive drinking and frequent drinking are often seen as normal and socially accepted behaviour. Family drinking habits also effects the children's drinking habits. ${ }^{3}$

One of the most distressing problems in alcoholism treatment is the relatively high rates of relapse to alcohol use following periods of abstinence. Although specific criteria for relapse or to differentiate relatively limited episodes of use from episodes that lead to a resumption of uncontrolled use have not been universally adopted (Donovan, 1996), relapse is generally defined as an episode of substance use following some period of abstinence. Many experts in the field view relapse as a crucial clinical issue (Brownell, 1986; Marlatt and Gordon, 1985: Rounsaville, 1986) ${ }^{4}$

\section{Statement of the Problem:}

A Descriptive Study to Assess the Prevalence of Alcoholism and Relapse Precipitants Among Alcoholic Persons in Selected Community, Jalandhar, Punjab.

\section{Objectives of the Study:}

1. To assess the prevalence of alcoholism in selected community.

2. To assess the prevalence of alcohol relapse among alcoholic persons in selected community.

3. To identify relapse precipitants among alcoholic persons in selected community.

4. To analyze the relationship of relapse precipitants with selected socio demographic variables such as age, education, occupation, type of family, history of alcoholism in family. 


\section{Purpose of Study:}

The aim of the study is to assess the prevalence and relapse precipitants among alcoholic persons in selected community.

\section{Delimitations:}

1. The population of the study is 112 males and the study is limited to 100 males that are included as the sample.

2. The study is limited to only males in selected community.

3. The study is limited to persons who can understand Punjabi language.

4. The study is limited to a specific area.

5. The study is limited to the persons who are willing to participate in the study.

\section{Review Of Literature:}

Divya Aggarwal, Anil Lal, R. Chandra (March 2009) ${ }^{5}$ conducted a study to examine precipitants leading to alcohol relapse among alcoholics in deaddiction centres and private clinics Ghaziabad nearby NCR (National Capital Region). Data was obtained by a semi structured interview technique. The sample consisted of 150 consecutive subjects. The study examines that the reason for the first use and regular use thereafter were almost the same in which the common reason were inability to concentrate, sleep disturbances, body aches, urge to alcohol, frustration, losses, sadness, family conflict, and peer influences.

S.K. Mattoo. S. Chakrabarti and M. Anjaiah (October, 2008) ${ }^{6}$ conducted a study to rule out the psychosocial factors associated with relapse in men with alcohol. The sample consisted of 30 patients from the population of the patients attending the drug de-addiction centre and treatment centre (DDTC) of the department of Chandigarh. Data was obtained by using the Severity of Alcohol Dependence Questionnaire (SADQ) and Relapse Precipitants Inventory (RPI) to assess high risk situations.

\section{Methodology:}

Research approach: A descriptive approach was used for the present study.

Research design: Non -Experimental research design was used for the present study.

Study setting: The study was conducted at village Sarai Khass, near CHC Kartarpur.

Sample: The study sample for analyzing prevalence were males of age group $20-50$ years and above and for analyzing relapse precipitants were the alcoholic patients of age group $20-50$ years and above residing in village Sarai Khass, near CHC Kartarpur.

Sample size: The study was conducted on total 1262 sample size, out of which 1162 were males of age group $20-50$ years and above and 100 were alcoholics with alcohol relapse.

Sampling technique: Purposive sampling technique was used for the selection of samples.

Tool for data collection: Data was collected using a self structured checklist to measure the relapse precipitants among the males. It contained 6 items (Situational crisis, social crisis, financial crisis, positive / pleasant internal states, negative / unpleasant internal states, others). The response of each item was in the form of yes or no. One person was allowed to tick more than one item so the analysis was on the basis of number of responses for each item.

The tool consisted of two sections:-

Section 1: - consisted of 5 items (age, education, type of family, occupation, family history) for obtaining the information on socio-demographic variables.

Section 2: - consisted of 30 items to assess the prevalence of alcoholics.

Data collection method: The method was as follows: -

- Written permission was obtained from Sarpanch of village Sarai Khass, near CHC Kartarpur, Jalandhar to collect data from that village. The purpose and objectives were discussed with sarpanch and verbal consent was taken from the subjects. Data collection was done in the month of February.

Data analysis: The collected data was analysed according to the objectives of the study using descriptive statistics. 


\section{Major Findings:}

According to Section I: Socio-Demographic Variables

Majority of respondents are of age group 50 and above (45\%). Most of them , matric pass (57\%) and most of them belongs to joint family (61\%), majority of them are self - employed (81\%), and most of them have history of alcoholism in first degree relatives $(59 \%)$.

\section{According to Section II:}

According to objective 1: - To assess the prevalence of alcoholism in selected community. In survey, nearly half of the population $(51.11 \%)$ is alcoholic.

According to objective 2: - To assess the prevalence of relapse among alcoholic persons in selected community.

About one - fifth (18.82\%) of the alcoholic persons show relapse rates.

According to objective 3: - To identify relapse precipitants among the alcoholic persons in selected community.

Positive /pleasant internal state is the relapse precipitant for majority of alcoholic persons (80). Hence it can be said that craving is the most precipitant factor for relapse of alcoholism followed by enjoyment and exposure to alcohol again. Stress is also important precipitant factor for relapse.

According to objective 4: - To analyze the relationship of relapse precipitants with selected socio demographic variables such as age, education, occupation, type of family, history of alcoholism in family.

- As the age increases, relapse rate also increases $(91.11 \%)$ due to positive / pleasant internal states.

- As the education increases, relapse rate decreases $(85.71 \%)$ due to positive / pleasant internal states.

- According to family type, nuclear families have more relapse rate $(92.30 \%)$ as compared to joint families $(75.40 \%)$.

- According to type of occupation, alcoholic persons doing non - government job show maximum relapse rate (80\%) as compared to government job (69.23\%) and self - employed (1.23\%).

- According to family history, alcoholic persons with no family history show maximum relapse rate (88.23\%) as compared to first degree relatives $(79.66 \%)$, second degree relatives $(77.77 \%)$ and third degree relatives $(83.33 \%)$.

\section{Recommendations:}

Based on the findings of the study following recommendations are offered: -

1. The study can be replicated on large sample to generalize the findings.

2. A similar study can be conducted to assess the prevalence of alcoholism and relapse precipitants among alcoholics among the age group below 20 years of age.

3. A comparative study can be conducted to assess the prevalence of alcoholism among males of rural and urban area.

4. A comparative study can be conducted to assess prevalence of alcoholism among adolescents and adults.

5. A comparative study can be conducted to assess the prevalence of alcoholism among males and females.

\section{Table Of Contents:}

Table: Prevalence of relapse among alcoholic persons in selected community area

\begin{tabular}{lcc}
\hline & N & Prevalence of Relapse \\
\hline Number of Alcoholics & 594 & $18.82 \%$ \\
Number of Relapse & 112 & \\
\hline
\end{tabular}

Table shows that out of total 594 alcoholics, 112 relapse cases are found which makes rate of prevalence of relapse to be $18.82 \%$.

Hence it can be said that relapse rate of alcoholism is low in selected community area. 
A Descriptive Study to Assess the Prevalence of Alcoholism and Relapse Precipitants....

Table: Relationship of relapse precipitants with Occupation

$$
\mathrm{N}=100
$$

Occupation n Situational Social Financial positive/pleasant Negative/unpleasant others

\begin{tabular}{|c|c|c|c|c|c|c|}
\hline & Crisis & Crisis & Crisis & internal states & internal states & \\
\hline Self & 7.40 & 3.70 & 9.87 & 1.23 & 22.22 & 46.91 \\
\hline \multicolumn{7}{|l|}{ Employment } \\
\hline Government 13 & 15.38 & 7.69 & 0 & 69.23 & 30.76 & 61.53 \\
\hline \multicolumn{7}{|l|}{ Job } \\
\hline Non & 20 & 0 & 0 & 80 & 20 & 40 \\
\hline
\end{tabular}

Table shows that alcoholic persons who are self employed shows relapse rate due to positive/ pleasant internal states i.e. $1.23 \%$, followed by government job i.e. $69.23 \%$ and followed by non - government i.e. $80 \%$ Hence it can be said that alcoholic persons doing non - government job show maximum relapse rate.

\section{References:}

[1]. Utalbasha N. Dhandargi. A study to assess the effectiveness of street play on alcoholism among young adults in selected area. Indian Journal of Psychiatry. 2007. $11-2$.

[2]. Rehm. Effects of alcoholism. Nightingale Nursing Times. 2004. $21-25$.

[3]. Kaplan and Sadock. Etiology and causes. Synopsis of psychiatry. $7^{\text {th }}$ edition. Williams and Wilkins. Publications. $398-9$.

[4]. Brownell. Marlaat. Gordon. Rounsaville. Studies to rule out factors in relapse to alcohol. Journal of studies on alcohol. 1999. 60 (1).

[5]. S.K. Mattoo. S. Chakrabarti. M. Anjaiah. Psychosocial factor associated with relapse in men with alcohol and opioid dependence. Indian Journal of Medical research. 2009. 130 (2). $702-708$

[6]. Divya Aggarwal. Anil Lal. R. Chandra. Relapse precipitants in alcohol addiction. Indian Journal Social Science Researchers. 2009. 6(1). $80-83$. 